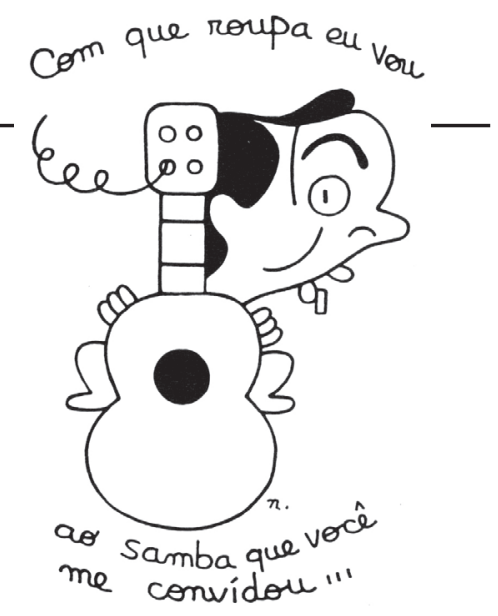

\title{
Duas crônicas e meia
}

\author{
Manuel Bandeira
}

Apresentaçăo de DECIO DE ALMEIDA PRADO

Manuel Bandeira, em suas Crônicas da Provincia do Brasil, evocou por mais de uma vez a atmostera de certa boemia carioca que reunia, freqūentemente em torno da música popular, desoe Catulo da Paixăo Cearense atê vila-Lobos, desde Sinhô até Tomás Terân, farnoso violonista uruguaio. Reproduzimos aqui em sua totalidade duas dessas crônicas, dedicadas ambas a Sinho, e uma terceira apenas pela metade - 0 suficiente para reviver o ambiente, animado pelo violăo e regado a conhaque, em que, no dizer do poeta, ligavam-se "os poetas, os artistas, a sociedade fina e cuitta às camadas profundas da ralê urbara".

\section{Na câmara-ardente de José do Patrocínio Filho}

A igreja do Rosário dos Pretos tem aspecto despojado e paupérrimo. É talvez a nave mais triste do Rio, porque com ser nua e modesta é bem grande e faz pensar na frase de Burton, a quen as igrejas brasileiras davam a impressāo de huge bams, celeiros ou paibis enormes. Ele dizia isso a propósito das belas igrejas mineiras do Aleijadinho. Na igreja do Rosário dos Pretos a impressăo de Burton ê justa.

Ali esteve exposto em câmara-ardente o corpo de José Carlos do Patroclnio Filho, o Zeca Patrocínio. Estive lâ depois de meia-noite e demorei-me uma hora vendo os clfios arder e ouvindo a conversa de amigos que recordavam casos da vida agitada e boémia do extinto. J. B. Silva, o Sinhô dos sambas estupendos, (năo arredara pé dali) me contava o fim de uma noitada em que o Zeca o intimou com um navalhăo cheio de dentes a fazer uma serenata sob as janelas da atriz Lia Binatti.

Quem tivesse encontrado uma vez com o Zeca tínha uma historia engraçada para contar, Eu conheci-o ultimamente, numa farra em certa casa inconfessável da rua Riachuelo. Estava lấ o Vila-Lobos, o Ovale, o Joåo Pemambuco, o Catulo. O violảo passava de mão em mảo, porque todos tocavam. Catulo estava impossivel. Bebera cerveja de mais e deu para declamar poemas. Nós querlamos que ele cantasse umas modinhas, bem bestas, bem pemósticas, como "A tua coma", ou "Clélia, adeus!" ou "Talento e formosura". Mas o bardo estava em maré de grandeza $e$ dizia muito sério a duas belezas venais:

- "Minhas senhoras, eu tenho sessenta anos e já li todos os grandes poemas de todas as literaturas; li todo o Homero, todo o Virgllio; li Goethe, Shakespeare, Ariosto: nunca encontrei nada cormo este poema da minha lavra que vou lhes recitar!"

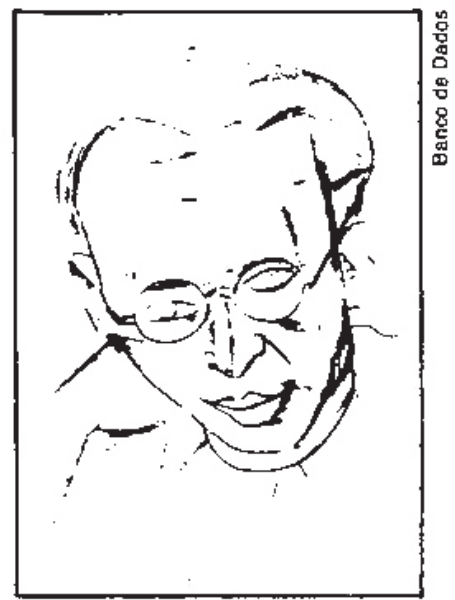

Bandeira; crayon de Lasar Segall 
Quando ele puxava o pigarro para começar e a versalhada parecia inevitável, o Zeca salvava a situaçäo:

- O Catulo, canta aquela modinha!

- Que modinha?

- Aquela em que vocé compara um pé a um pensamento de Pascal.

E como Catulo estava por conta da cerveja, esquecia imediatamente o poema e cantava a modinha pedida.

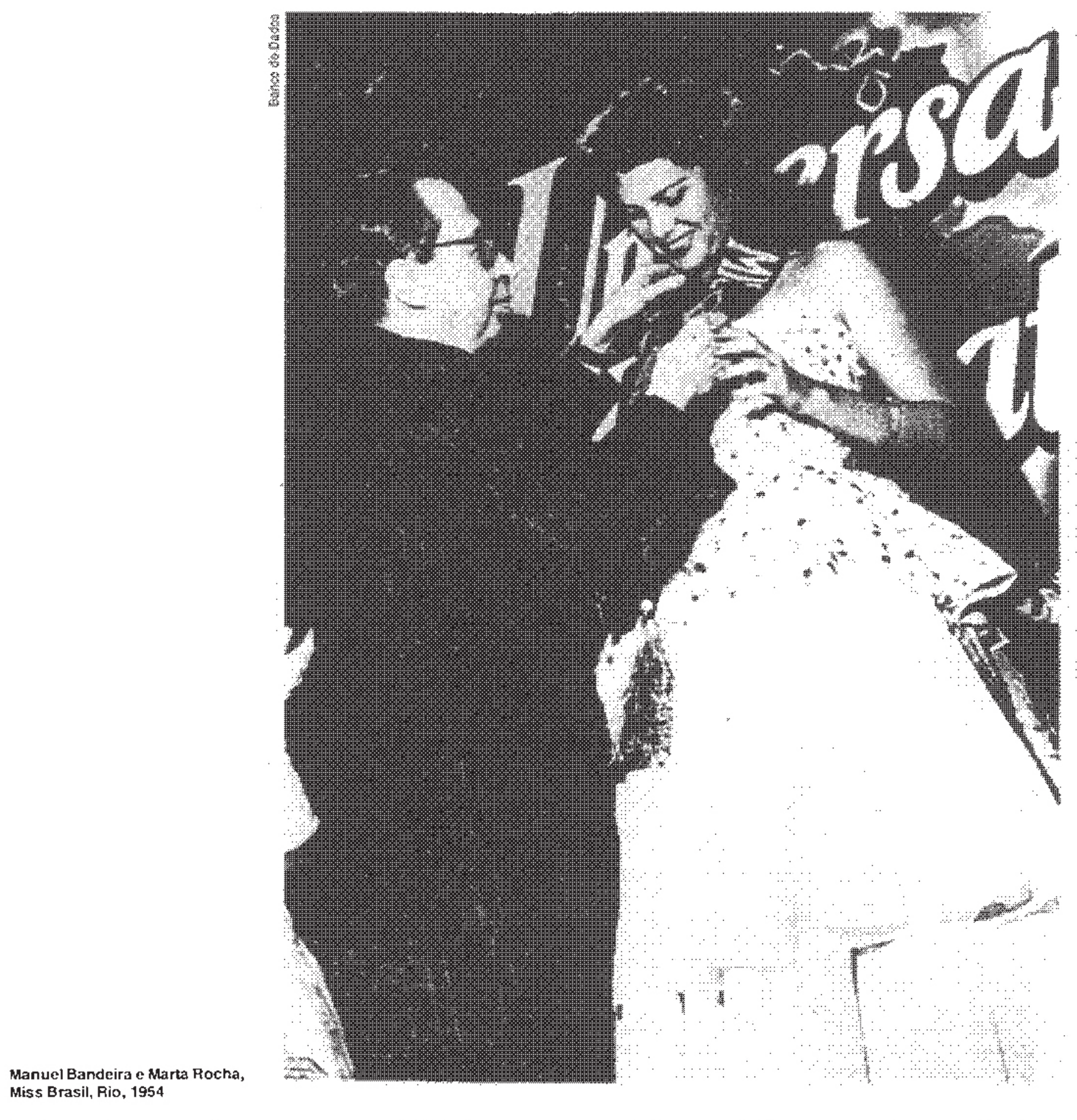




\section{O enterro de Sinhô}

J. B. Siva, o popular Sinhß̊ dos mais deliciosos sambas carocas, era um desses homens que ainda morrendo da morte mais natural deste mundo dæo a todos a impressăo de que morreram de acidente. Zeca Patroclnio, que o adorava e com quem ele tinha grandes afinidades de temperamento, era assim tamberm: descarnado, Ilvido, frangatho de gente, mas sempre fagueiro, vivaz, agillssimo, dir-se-ia um moribundo galvanizado provisoriamente para uma farra. Que doença era a sua? Parecia um ł́fsico nas últimas. Diziam que tinha muita sffilis. Certamente o rim estava em pantanas. Flgado escangalhado. Ouvia-se de vez em quando que o Zeca estava morrendo. Ora em Paris, ora em Todos os Santos, subúrbio da Central. E de repente, na Avenida, a gente encontrava o Zeca às três da madrugada, de smoking, no auge da excitação e da verve. Assim me aconteceu uma vez, e o que o punha tão excitado naquela ocasiāo era precisamente a última marcha carnavalesca de Sinhó, o famoso "Claudionor"...

"que pra sustentar familia

foi bancar o estivadot..."

Me apresentaram a Sinhó na câmara-ardente do Zeca. Foi na pobre nave da igreja dos pretos do Rosário. Sinhô tinha passado o dia ali, era mais de meia-noite, ia passar a noite ali e não parava de evocar a figura do amigo extinto, contava aventuras comuns, espinafrava tudo quanto era músico e poeta, estava danado naquela época com o Vila e o Catulo, poeta era ele, músico era ele. Que Ifingua desgraçada! Que vaidade! mas a gente nāo podia deixar de gostar dele desde logo, pelo menos os que sāo sensíveis ao sabor da qualidade carioca. O que há de mais povo e de mais carioca tinha em Sinhố a sua personificação mais típica, mais genulna e mais profunda. De quando em quando, no meio de uma porção de toadas que todas eram camaradas e frescas como as manthăs dos nossos suburbiozinhos humildes, vinha de Sinhô ưm samba definitivo, um "Claudionor", um "Jura", com um "beijo puro na catedral do amor", enfim uma dessas coisas incrlveis que pareciam descer dos morros lendários da cidade, Favela, Salgueiro, Mangueira, São Carlos, fina flor extrema da malandragem carioca mais inteligente e mais heróica... Sinhó!

Ele era o traço mais expressivo ligando os poetas, os artistas, a sociedade fira e culta às camadas profundas da ralê urbana. Dal a fascinação que despertava em toda a gente quando levado a um salẫo.

Vi-o pela última vez em casa de Alvaro Moreyra. Sinhô cantou, se acompanhando, o "Não posso mais, meu bem, não posso mais", que havia composto na madrugada daquele dia, de volta de uma farra. Estava quase inteiramente afonnico. Tossia muito e corrigia a tosse bebendo boas lambadas de Madeira R. Repetiu-se a toada um sem número de vezes. Todos nós secundávamos em coro. Terán, que estava presente, ficou encantado.

Nāo faz uma semana eu estava em casa de um amigo onde se esperava a chegada de Sinhó para cantar ao violāo. Sinhố năo veio. Devia estar na rua ou no fundo de alguma casa de música, cantando ou contando vantagem, ou entāo em algum botequim. Em casa é que năo estaria; ern casa, de carna, é que não estaria. Sinhô tinha que morrer como morreu, para que a sua morte fosse o que foi: um episódio de rua, como um desastre de automóvel. Vinha numa barca da tlha do Governador para a cidade, teve uma hemoptise fulminante e acabou.

Seu corpo foi levado para o necrotério do Hospital Hahnemaniano, ali no coração do Estácio, perto do Mangue, à vista dos morros lendários... A capelinha branca era muito exigua para conter todos quantos queriam bem ao Sinhô, tudo gente simples, malandros, soldados, marinheiros, donas de rendez-vouz baratos, meretrizes, chauffeurs, macumbeiros (lá estava o velho Oxuná da Praça Onze, urn preto de dois metros de altura com uma belida num olho), todos os sambistas de farna, os pretinhos dos choros dos botequins das ruas Júlio do Camo e Benedito Hipólito, mulheres dos morros, baianas de tabuleiro, vendedores de modinhas... Essa gente não se veste toda de preto. O gosto pela cor persiste deliciosamente mesmo na hora do enterro. Há pros. titutazinhas em tecido opala vemelho. Aquele preto, famanaz do pinho, traja uma fatiota clara absolutamente incrivel. As flores estão num botequim em frente, prolongamento da cămara-ardente. Bebe-se desbragadamente. Um vaivếm incessante da capela para o botequim. Os amigos repetem piadas do morto, assobiam ou cantarolam os sambas ("tu te lembra daquele choro?"). No cinema da rua Frei Caneca ưn bruto cartaz anunciava "A última canção" de Al Johnson. Um dos presentes comenta a coincidência. O Chico da Baiana vai trocar de automovel e volta com um landaulet que parece de casamento e onde toma assento a famtlia de Sinhó. A Pérola Negra, bai-
J. B. Silva, o "Sinho", em traço de Alvarus. Note-se o semblante arguto e a elegáncia do "popular'ssino rei do sambe"

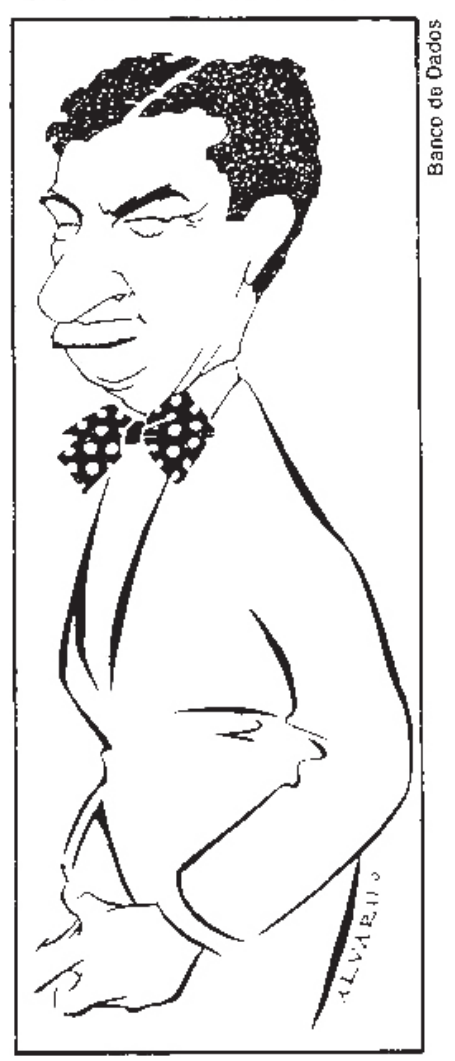




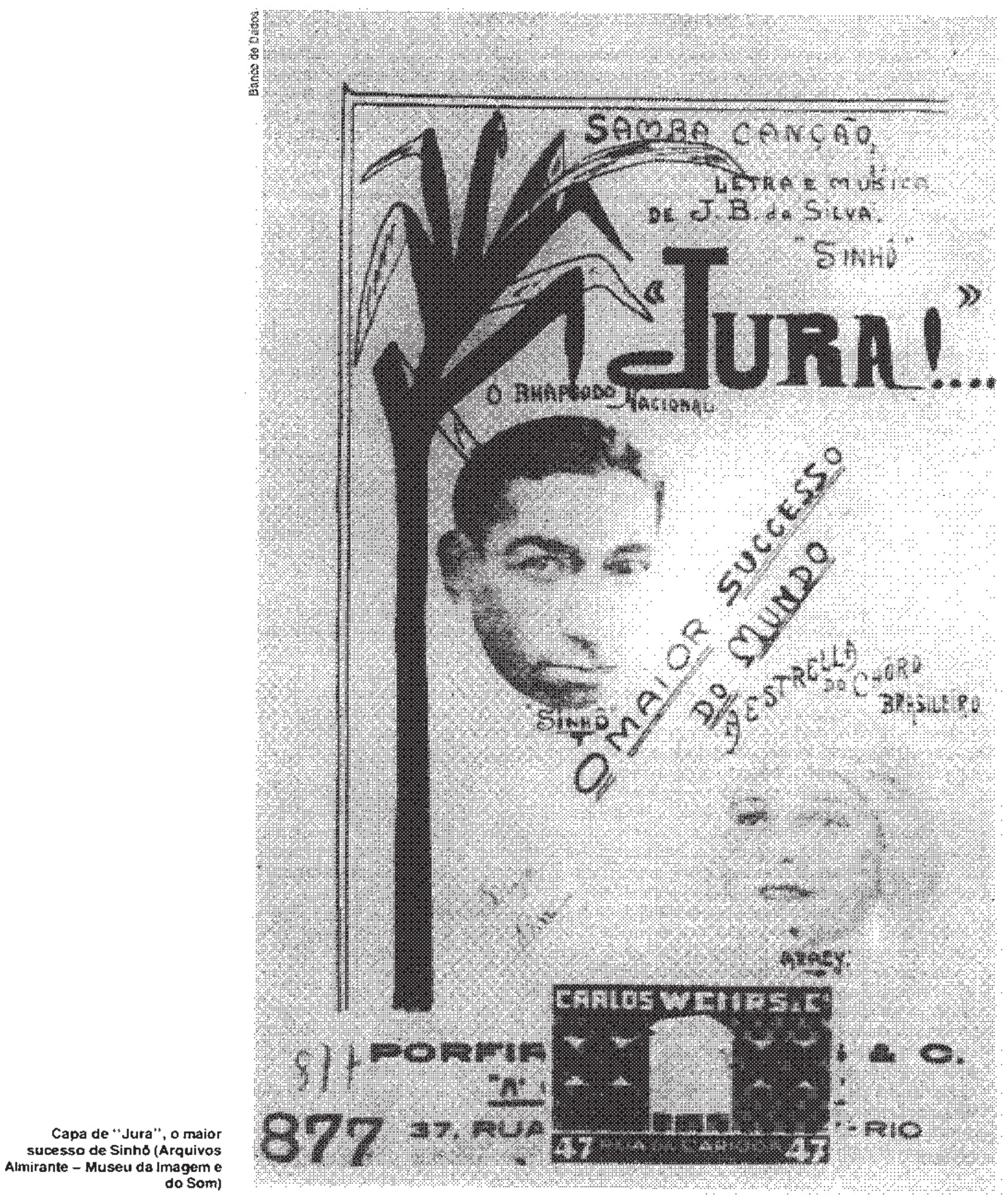


larina da companhia preta, assume atitudes de estrela. Năo tem ali ninguêm para quebrar aquele quadro de costumes cariocas, seguramente o mais genuíno que já se viu na vida da cidade: a dor simples, natural, ingénua de um povo cantador e macumbeiro em torno do corpo do companheiro que durante tantos anos toi por excelência intérprete de sua alma estóica, sensual, carnavalesca.

\section{SAMBISTAS}

Quando morreu o afamado Sinho, escrevi para o Diário Nacional de Sảo Paulo uma crônica em que recordava com saudade alguns traços curiosos da figura do rei do samba carioca. E contei uma cena a que tive o prazer de assistir em casa dos meus amigos Eugénia e Álvaro Moreyra. Foi o caso que numa das extintas deliciosas quintas-feiras em que o casal recebia, apareceu o Sinhô e regalou os convidados nåo só com a sua conversaçāo como com os seus sambas. Estava mal de voz, tossia muito (era a velha iuberculose que apertava o cerco), mas menhum de nós teve a menor idéia de atribuir aquela tosse à terrivel moléstia e, como era do mais elementar dever, poupar o doente. O que nos desculpa caquela descaridace é que Sinhó para toda a gente era uma criatura fabulosa vivendo no mundo noturno do samba, zona impossivel de localizar corn precisão, - ê no Estácio mas bem perto ficam as macumbas do Encantado, mundo onde a impressāo que se tern é que ali o pessoal vive de brisa, cura a tosse com álcool e desgraça pouca é bobagem. Assim, quando Sinhô parava num acesso, ia-se buscar uma boa lambada de Madeira e o fato es que a tosse passava.

A acreditar no Sinho, ele năo tinha dormido na noite da véspera. Passara-a numa farra, e naquela manhã mesmo, ao regressar a casa, năo fora bem recebido pelo seu bem, que naturalmente estava ralado de ciúmes. Contou Sinhô que foi entāo para o piano e improvisou um samba que entoou para nos ainda com as hesitaçőes das coisas inacabadas. Era gostosissimo e parecia do melhor Sinhô. (Ninguém duvidou que fosse dele). Lembro-me bem da toada e da letra do estribilho:
Já é demais,
Meu bem, já é demais!
Eu já notei que tu queres me acabar...

Fizemos o Sinhó repetir a toada um sem número de vezes. Todos os presentes já a sabiam de cor e secundavam em coro quando chegava a hora do "já é demais". Foi isso em fins de 29.

Há pouco mais de um mês um amigo meu, que se interessa atualmente por modinhas policiais, pediu-me umas informaçð̌es, e para servi-lo andei correndo os olhos na literatura de cordel. Fui à toa à Praça Tiradentes onde sob as arcadas do antigo S. Pedro havia um vasto estenderete do gênero. $O$ café da esquina da rua das Marrecas estava em demoliçăo. Mas passando por lá de bonde verifiquei que nos andaimes da reconstruçåo os cordelinhos do engraxate resistiam bravamente á poeira. Lâ pude arranjar uma pequena coleçāo de "lyras" que remontavarn até 1927.

Vim para casa e correndo a vista por aquelas páginas sujlssimas deparei num dos cademos conn o titulo "Jấ é demais". Abaixo dele vinha a informação: "Letra e música de seu Candu". Ora, lá estava o estribitho do samba de Sinho:

\section{Já é demais, meu bem \\ Meu bem já é demais! \\ E hoje já notei \\ Que tu queres me acabar...}

Verifiquei logo que o plágio nấo podia ser de seu Candu, porque a publicaçåo era de 1927 (editor Menotti Camaval, deposito rua General Pedra 169) e de resto havia ainda a indicaçåo abai* xo do tftulo de que o "Já ê demais" era choro do carnaval de 1925, o que estava aliás provadíssimo pelo contexto da letra todo cheio de alusōes aos fatos revolucionários de 24:

Lá no morro de S. Carlos

E'lugar de pretensão.

Já botaram metralhadoras

P'ra brigar com aviaçāo. 


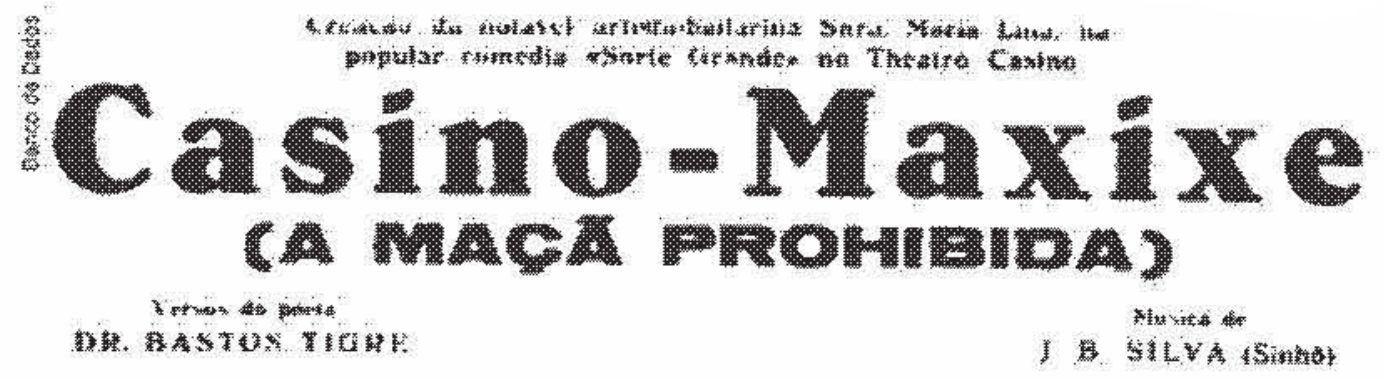

Capa de "Casino-Maxixe", com a caricatura de Sinho feita por Kalixto, onde se lé: "Sinhô, o popularíssimo rei do samba"

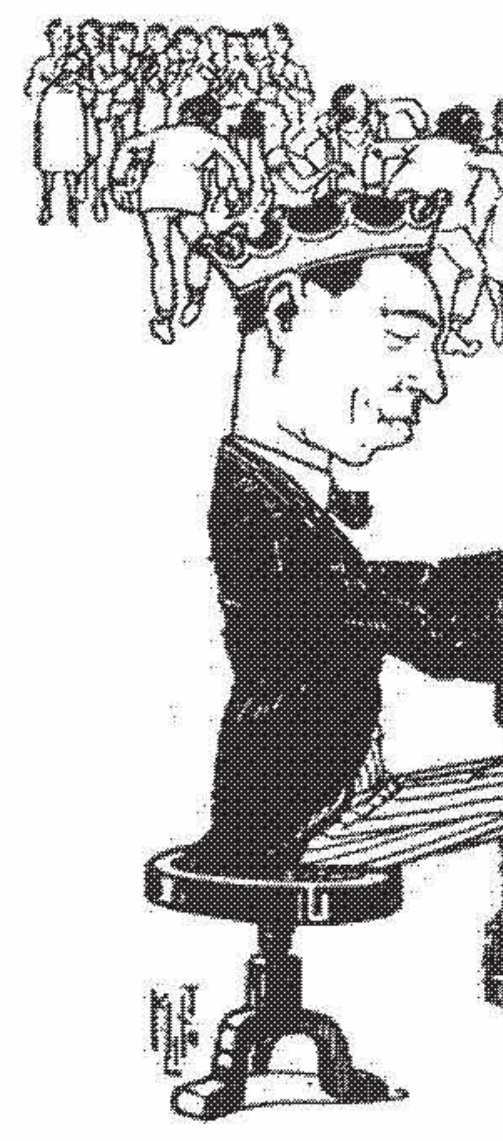

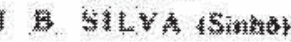

